Research, part of a Special Feature on Scenarios of global ecosystem services

\title{
Linking Future Ecosystem Services and Future Human Well-being
}

\author{
$\underline{\text { Colin D. Butler }}^{1}$ and Willis Oluoch-Kosura ${ }^{2}$
}

\begin{abstract}
Ecosystem services are necessary, yet not sufficient for human well-being (however defined). Insufficient access to the ecosystem provisioning service of food is a particularly important factor in the loss of human well-being, but all ecosystem services contribute in some way to well-being. Although perhaps long obvious to ecologists, the links between ecosystems and aspects of human well-being, including health, have been less well understood among the social science community. This situation may now be starting to change, thanks in part to the Millennium Ecosystem Assessment (MA). Causality between ecosystem services and well-being is bidirectional; it is increasingly clear that functioning societies can protect or enhance ecosystem services, and accordingly, that societies with impaired well-being (best documented in the case of chronic diseases such as malaria and HIV/AIDS) can also experience a related decline in ecosystem services.
\end{abstract}

The future state of human well-being and of ecosystem services is more than the co-evolution of these two fundamental elements. Human well-being also depends, critically, upon the human institutions that govern relationships between human individuals and groups, and also between humans and ecosystem services.

The scenarios working group of the MA found that human well-being is highest in the Global Orchestration scenario, which assumes the fastest evolution of beneficial institutions, and is lowest in the Order from Strength scenario. Human well-being was found to be intermediate in the other two scenarios (Adapting Mosaic and Techno-Garden) even though these scenarios share a much greater recognition of the importance of ecosystem services to human well-being.

Key Words: cognitive potential; conflict; ecosystems; health; human well-being; hunger; nutrition; scenarios; surprise

\section{INTRODUCTION: ECOSYSTEM SERVICES AND HUMAN WELL-BEING}

The concept of human well-being is complex, controversial, and continually evolving. The linkages between human well-being and ecosystem services are even more complex. And although some of these links are recognized, many remain poorly understood and controversial (Balmford et al. 2005, Butler et al. 2003).

Ecosystem services are clearly necessary, yet not sufficient for human well-being. Humans are social, thinking, and hierarchical beings. Context, expectations, relationships, social position, and a sense of participation and inclusion have many bearings on the subjective experience of well-being.
These have little to do with ecosystem services directly. In addition, human actors, operating at scales that are local, regional, and increasingly, global, have a substantial influence on the availability and quality of ecosystem services. Increasingly, human actions have remote effects, including on other people who are effectively invisible, far removed by distance, culture, and socioeconomic position.

A continuous supply of ecosystem services is integral to provide many material factors essential for human well-being, such as shelter, clothing, food, and livelihood. But once a material minimum is attained, human well-being is substantially experiential. These non-material aspects of human well-being have been defined as including good 
health, a sense of security, good social relations, freedom, and choice (Butler et al. 2003). These idealized components of well-being should not be confused with a life free from all difficulty. The life of virtually every human being has some pain and suffering, and experiences such as occasional bereavement and anxiety do not necessarily signify poor human well-being. However, many people with poor well-being have lives in which suffering is pervasive, and in which hope, opportunity, and freedom are perennially limited.

Even though some of the main elements of human well-being (including the feeling of security) can be considered psychological, these psychological aspects are shaped by and reflect material circumstances, including access to adequate ecosystem services. In many cases, an insufficiency or maldistribution of ecosystem services contributes to a sense of insecurity, and often, to poor social relations. This insufficiency may, in some cases, be subjectively perceived, rather than observed by a "dispassionate" watcher. Adams et al. (2003) point out that conflicts over the management of common pool resources are rarely if ever purely "material," but rather are crucially dependent on the perceptions of the protagonists. They also point out that decision makers and stakeholders, particularly if from different backgrounds, are likely to differ in their access to and understanding of diverse sources of knowledge. In some cases, religious beliefs and moral conviction are also important in structuring understanding and determining conflict or its absence.

The apprehension of "future" ecosystem service insufficiency appears to sometimes impel more powerful groups to act pre-emptively to protect their existing resource access, even though that access is, by definition, disproportionately high. An example of this appears to have occurred during the Rwandan genocide, in which much conflict arose over the struggle to control productive land, and hence to capture and retain the security that access to the ecosystem services of productive land affords. Many instigators and victors of this conflict were not completely impoverished or landless, but appear to have been slightly better off than the poorest and most vulnerable. Responding to a social milieu that briefly permitted and even promoted extreme violence, many of this group appear to have used the opportunity of genocide to increase their comparative affluence. In contrast, some of the absolute poorest (who disproportionately succumbed in the genocide) had committed comparatively minor crimes in the period before the genocide. These people, known as "voleurs par faim" (thieves by reason of hunger), were generally tolerated before the genocide, but were probably disproportionately vulnerable during it (André and Platteau 1998).

Although understanding of the emergence of the Rwandan genocide remains inadequate and contested, a relationship between conflict and the perception of actual - and a future worsening of ecosystem scarcity seems undeniable. Many other conflicts, both historical and contemporary, are also related to the control of productive land, valued because of its ability to provide ecosystem services.

\section{Soil Depletion, Poor Nutrition, and Human Well-being}

The title and content of a recent article in the leading medical journal The Lancet, "Hunger in Africa: the link between unhealthy people and unhealthy soils" (Sanchez and Swaminathan 2005), reflect a welcome and growing recognition of the link between ecosystem services and human well-being within parts of the health and social science literature. However, only a moment's reflection is needed to realize that the causal relationship between tired, nutrient-depleted soil and tired, sick people is bidirectional and reinforcing (see Fig. 1). In other words, populations that experience poverty and ill-health, in part because of under-nutrition and material lack from soil exhaustion, are also likely to be relatively deficient in the human capability needed to improve local soil quality.

Sanchez and Swaminathan (2005) state that "the major economic reason for lack of fertilizer input has been the poor infrastructure in rural areas of subSaharan Africa." However, calling this the "major" reason is misleading. It is well recognized that the cost of transport of both crop inputs (e.g., fertilizer) and outputs (e.g., cash crops) inhibits economic development in many parts of Africa, by making locally grown crops too expensive to compete with cheaper imported food (Verhye 2000). However, the quality of transport systems in many parts of sub-Saharan Africa has deteriorated in recent decades, and this in turn has numerous causes, including some that are economic, some that are local, and some that are global. 
Fig. 1. A complex, interlinked network of factors operate to perpetuate poverty in much of the developing world, including sub-Saharan Africa. Literally dozens of economic, political, and social factors can be identified as contributing to a causal web that effectively serves to lock in poverty, poor governance, and undernutrition. Many of these factors are bi-directional, such as the relationship between poor governance, chronic disease, and poverty. Successful implementation of the Green Revolution appears to be an important factor that could alleviate much of the poverty in sub-Saharan Africa. However, a plethora of factors (some of which are global) inhibit this. The figure attempts to convey the as yet undelivered promise of the Green Revolution as lightning flashes that try, but ultimately fail, to connect (and thus alleviate) governance and soil nutrient depletion.

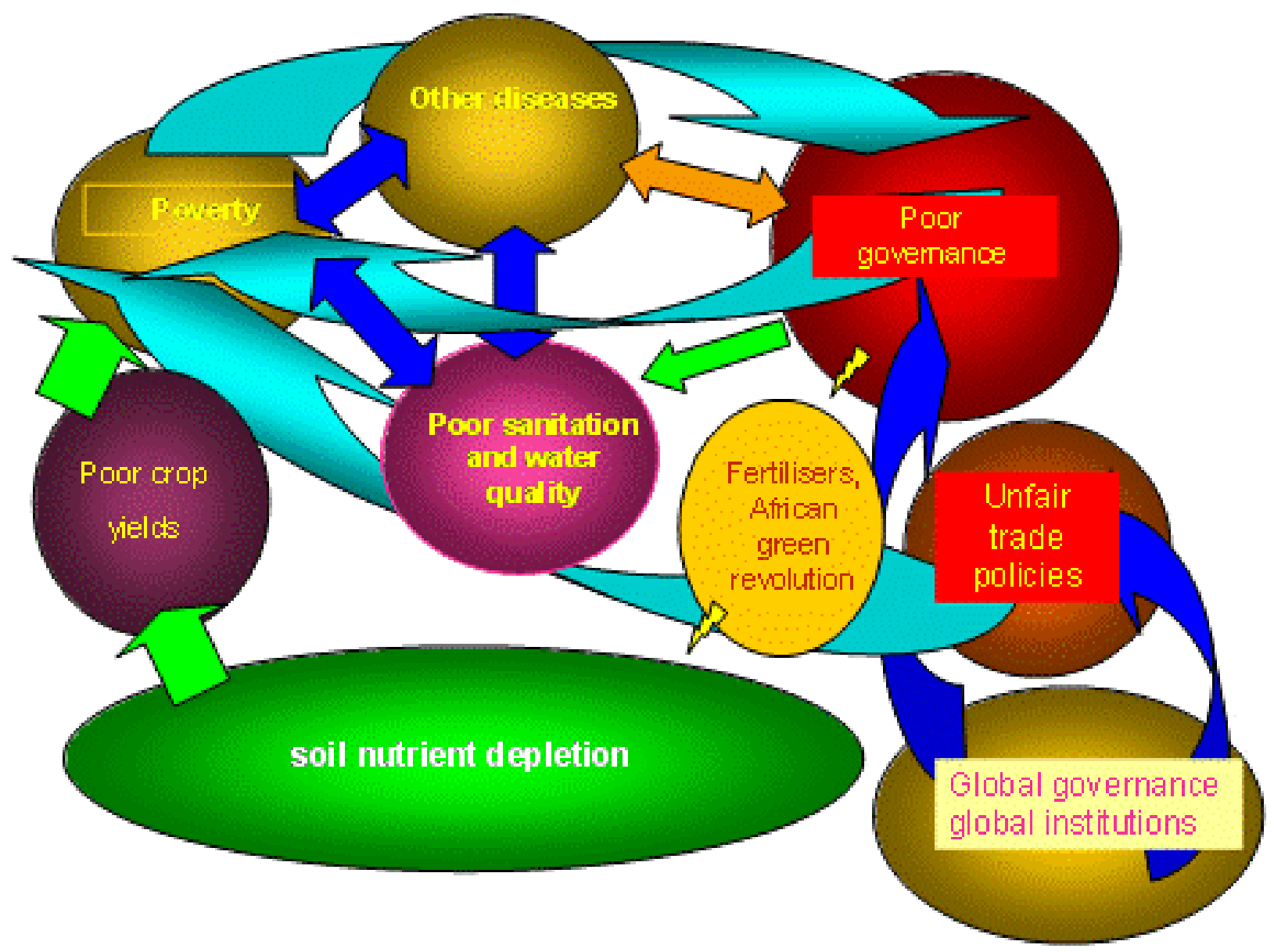

In fact, as partly recognized by Sanchez and Swaminathan (2005), a vicious circle of factors operates to perpetuate poverty in much of the developing world, including in sub-Saharan Africa. Literally dozens of economic, political, and social factors can be identified as contributing to a causal web that effectively serves to lock in poor soil quality. Some of these factors, such as co-existent disease (e.g., malaria, HIV/AIDS, and the usual diseases of poverty caused by contaminated water, food, air, and soil), poor governance (e.g., corruption, capital flight, brain and talent drain, high indebtedness, and mismanagement), and lack of education, credit, and adequate transport are shown in Fig. 1. When these factors are combined with the need for an annual harvest, together with the additional demand created by a growing population (co-existent in many parts of the developing world 
marked by undernutrition), it is clear that, without counter-measures, soil "mining" will aggravate the depletion of soil nutrients, and thus ongoing soil and human poverty. Impoverished humans, without assistance, are unlikely to break out of this cycle, in which ecosystem services and human well-being both decline.

\section{The Human Factors that Steal Intelligence from More than Two Billion People}

A lack of access to the ecosystem provisioning service of food causes far more than psychological harm: it robs thousands of millions of people of mental and physical potential by reducing intelligence and physical growth, in some cases from the moment of human conception. Undernutrition was recently assessed as an underlying cause of more than half of the 10.6 million deaths that occur each year, worldwide, of children under the age of five (Bryce et al. 2005).

Undernutrition is particularly common in subSaharan Africa and South Asia, especially in India (de Onis et al. 2004). In association with other factors such as disease and environmental contamination, it robs as many as one in three of the 6.5 billion people alive today of part of their potential intelligence quotient. The intelligence of populations has little if anything to do with genetic factors, but much to do with human access to adequate nutrition (Grantham-McGregor 2002), vulnerability to disease (Dillingham and Guerrant 2004), access to stimulation and opportunity, and exposure to certain forms of pollution, such as lead (Tong et al. 2000).

Undernutrition is more than an inadequate intake of energy and protein in food: it also refers to more subtle deficiencies of micro-nutrients, particularly of iron, which is essential to deliver oxygen to tissue, and thus needed for stamina. People who are physically stunted and mentally dulled are more vulnerable to manipulation and abuse than are those with more advantages, opportunities, and resources. They are also more vulnerable to diseases that lead to further impairment, such as malaria, tuberculosis, and, in some cases (especially women), HIV/AIDS. Despite periodic waves of public support for Third World debt relief, the number of people who benefit from the disadvantage of others and who are yet prepared to reduce their own advantage is modest at best (Pogge 2004).
Inadequate nutrition does not occur because of any absolute, "global" shortage of calories, vitamins, or the other micronutrients needed to ensure human development. Instead, there is a significant maldistribution of human access to the vital ecosystem provisioning service of food. Amartya Sen (1981) has described the root cause of hunger as a lack of food "entitlement," including the income needed to purchase food. However, although Sen's concepts were a useful counterweight to a thenprevalent view that famine was principally caused by ecological factors, the pendulum may have swung too far: attribution of hunger entirely to "human" factors is itself over-simplistic.

\section{The Interacting Social and Ecological Factors that Reduce Access to Provisioning Ecosystem Services}

The great Bengali famine, which caused over three million premature deaths during World War II, was, as Sen has shown, aggravated by human action (Sen 1981). The response of the British-controlled Indian government to a coalescence of environmental, ecological, and social factors that had depressed the 1942 rice supply (a cyclone followed by flooding and a fungal outbreak in Bengal was exacerbated by loss of rice imports from Burma, then held by the Japanese) can be seen, in hindsight, as dysfunctional. It led to food hoarding and a steep increase in the price of grain. Sen found that the total food supply in the year of maximum starvation (1943) actually exceeded that of 1941, a year when there was no famine. But although this famine can be analyzed as having human causation, it also had underlying adverse climatic and ecological factors.

The "Great Hunger" in the 1840s in Ireland, which led to a significant depopulation because of starvation, disease, and emigration (WoodhamSmith 1962), can similarly be analyzed as being generated by interacting ecological and human factors. The current undersupply of food in Zimbabwe is widely acknowledged to have been worsened by poor governance, corruption, and the replacement of the management of productive farms by people with less human and financial capital. Periodic drought has also played a role. As well, the total supply of human capital in Zimbabwe has been diminished by the devastating scale of the HIV epidemic. This has reduced agricultural (de Waal and Whiteside 2003) and other forms of social capacity. 


\section{Regulating Ecosystem Services and Human Well-being}

Regulating ecosystem services, at local, regional, and global scales, are also important for human wellbeing. Examples of regulating services include the reduction of soil erosion by adequate vegetation, and the buffering of coastal areas against storms and sea surges by mangroves, (Primavera 2005) wetlands, and beach forests (Danielson et al. 2005). The spatially varied destruction of infrastructure from Hurricane Mitch in 1998 (which cost 11000 lives) was widely attributed to deforestation, as well as waterlogging, poverty, and inadequate evacuation (Hellin et al. 1999). A recent review (FAO and CIFOR 2005) has questioned the capacity of forests and forest litter to govern water flow through mitigation of floods, some landslips, and by maintaining water flow during dry periods. However, rather than denying that any such regulating function exists, this report stresses the role of contributing factors, pointing out that many floods are inevitable even where forests are intact. Regulating services also contribute to provisioning services, e.g., by reducing soil erosion and providing micro-climatic conditions beneficial to crop production. On a global scale, climate is in part regulated by ecosystems, including land cover, soil organisms, and phytoplankton (Falkowski et al. 2000).

There is compelling evidence that many tribal, traditional, and historical societies had (and in some cases still possess) an understanding of the importance of ecosystem regulating services. This is demonstrated by, e.g., customs that help retain biodiversity, protect against excessive land clearing, and maintain water quality (Kirch 1997, Ramakrishnan et al. 1998, Atran et al. 1999, Berkes et al., 1998, Berkes 2003, Folke 2004). Correspondingly, there is substantial evidence that, today, a large and growing gap separates many people, especially those in urban areas, from sufficient appreciation of the importance of many regulating (and even provisioning) ecosystem services.

\section{Cultural Ecosystem Services and Human Well- being}

Cultural ecosystem services refer to the aesthetic, spiritual, psychological, and other non-material benefits that humans obtain from contact with ecosystems. Many indigenous people retain heartfelt, spiritual bonds with sacred landscapes, groves, and species. Many people, uprooted from intense daily contact with nature, nevertheless appear to appreciate and benefit from cultural ecosystem services (Frumkin 2002). Such contact need not be direct, as illustrated by the popularity of the virtual experience of distant ecosystems. Nor need such contact be exotic, as shown by the ubiquity of gardens, pets, potplants, and images of nature on computer screens.

Cultural services contribute especially to health. Many farmers form emotional bonds with the herds and flocks they depend upon for their livelihood (Zinsstag and Weiss 2001). Hospitalized patients recover faster if they can look out a window facing trees instead of bare walls (Ulrich 1984). Contact with pets improves health for survivors of myocardial infarction (Friedmann and Thomas 1995), reduces the incidence of minor health problems (Serpell, 1991), and improves the health of isolated and aged individuals.

Many cultures and societies retain a myth of an Eden, an attractive, harmonious, and idyllic environment, characterized by an abundant supply of ecosystem services in proportion to the human demands for these services. Many wealthy individuals exhibit an appreciation for cultural ecosystems, e.g., by living in comparatively leafy suburbs or estates, or by holidaying in areas that are remote, beautiful, and comparatively wild.

The seemingly simple, obvious love and appreciation of many humans for nature may actually be profound. Biophilia (Wilson 1984) may express an innate human attraction to nature (Berkes et al. 1998), plausibly reflecting an evolutionarily driven understanding of human dependence upon ecosystem services. The neural links that express the emotional and experiential sensation of biophilia may be hard-wired into the human brain, both reflecting and helping to preserve many provisioning and regulating services. If so, this illustrates another example of the complex dynamic relationship between ecosystem services and human well-being.

Yet despite the plausibility of this hard-wiring, competitive forces have driven many societies to consistently sacrifice cultural and regulating ecosystem services for more prosaic needs, especially for provisioning services. In China, for 
example, nature has been relentlessly transformed; even as whole forests have been transformed to agricultural fields, some individual trees were retained and venerated (Elvin 2004, Tickell 2004). Many wetlands and mangroves have been cleared to improve provisioning services, such as shrimp farming (Primavera 2005).

\section{SCALE, POWER, AND ECOSYSTEM SERVICES}

Issues of scale and external force have frequently overwhelmed the capacity of local populations to apply customs and knowledge to maintain provisioning, regulating, and culturally enriching services critical for well-being. These services have sometimes been deliberately eroded by the actions of more powerful populations, seeking to enhance their own well-being. The slaughter of the buffalo in the American Midwest undermined the food supply for Amerindian populations; its cruelty and waste undoubtedly damaged morale, through loss of a key cultural (as well as a provisioning) service. The loss of the buffalo must also have altered the regulating service provided to the prairie by these large and numerous grazers. The invading human population was then able to establish a different provisioning service-the raising of crops and cattle.

Similar processes continue today in many developing countries. In Indonesia, illegally operating logging gangs contribute to the rapid disappearance and fragmentation of forests and cultures (Jepson et al. 2001). The seasonal haze over large parts of Southeast Asia, caused by land clearing, peat fires (Page et al. 2002), and logging, reflects both local and external factors. Although land clearing by burning is a traditional practice in this part of the world, the vast haze during the severe El Niño of 1997-1998, which speculatively could be evidence of anthropogenic climate change (Trenberth and Hoar 1996), was of unprecedented size (Siegert et al. 2001). It caused significant adverse health and economic effects, including for many urban populations.

The unusually severe drought in the Sahel in the 1970s reduced Sahelian provisioning services, leading to the starvation of up to a million people (Foley et al. 2003). More recently, there has been appreciation that the unusual severity of this drought, especially in the eastern Sahel, may have been caused in part by climatic factors arising from European air pollution (Lelieveld et al. 2002). If so, this would represent an unconscious, accidental example of resource deprivation by people in other ways almost entirely disconnected to the Sahel nomads. The forecast impact upon low-lying island states because of sea-level rise, extreme weather events, and other manifestations of global climatic change is a less benign illustration of how powerful, distant, and large-scale actors continue to act remotely in ways that will damage ecosystem services vital for the well-being of other (less powerful) humans. A similar case is the pollution of rivers by foreign mining companies seeking to maximize profit, that results in loss of ecosystem services, such as occurred when tailings from a mine in Papua New-Guinea contaminated the Fly and Ok Tedi rivers (Macintyre and Foale 1997). In all these cases, more powerful, often remote, populations are damaging local ecosystem services in ways that enhance their own well-being at the expense of local, less powerful communities.

\section{The Distribution of Ecosystem Services and Human Well-being}

The distribution of human well-being follows the distribution of its constituents and determinants (such as income, hunger, food, freedom, and choice) in being grossly unequal. The per capita access to, and use of, ecosystem services is also distributed in a highly unequal way, but one that may be less skewed than that of well-being as a whole. For example (and despite the examples above), some indigenous peoples still retain access to a comparatively high per capita supply of locally available provisioning, regulating, and culturally enriching services. However, the well-being of many of these people is rarely as proportionally high, because of factors such as a low monetary income, disease, and associated vulnerability.

The constituents of well-being for many tribal and indigenous people are vulnerable to many outside forces, some of which operate unintentionally, rather than as deliberately oppressive instruments. For example, many indigenous populations in the Amazon now experience outbreaks of malaria, introduced by infected human migrants and disseminated by mosquitoes whose abundance has been increased by landscape changes, including deforestation and the introduction of water-holding plastic containers, which accumulate as litter (Patz 
et al. 2004). In the Arctic, there is accruing evidence for a decline in human health (including neurodevelopment) caused by consumption of pollutants found at high levels in fish and marine mammals because of bioaccumulation (Webster 2004, 2005) and also because of soil contamination at high altitudes and high latitudes (Blais et al. 1998). Although these long-range effects are rarely deliberate, the disparity of power between the causal and the affected population means that the injury is likely to be long prolonged. Few industrialized populations are likely to reduce their pollution when the main victims are unseen, distant, and poorly documented (Butler and McMichael 2006).

The well-being of isolated populations who retain comparatively high access to many ecosystem services may also, sometimes, be reduced by exposure to other cultures. This may be fostered by the planting and nurturing of wants that prove impossible to achieve. In some cases, overt exploitation and repression can occur, generating despair, depression, alcoholism, and violence-for which exposure or re-exposure to nature is an insufficient healer. Sometimes, these unwanted consequences may occur even where the per capita access to ecosystem services of the affected populations remains objectively high. Note, however, that we are not arguing that indigenous and other populations largely separated from the modern "developed" world inhabit a kind of Eden, in which they should be imprisoned (Mukta and Hardiman 2000). It is, furthermore, unlikely that well-being has ever been the universal experience of any people; exploitation, domination, and unhappiness are ancient phenomena (Price and Feinman 1995).

Our point is that well-being depends on a plethora of contextual factors, many of which cannot be provided by access to ecosystem services. A minimum set of ecosystem services may be necessary for well-being, but this is rarely if ever sufficient. However, descent into despair upon exposure to the modern world is not inevitable. In many cases, external social forces can create a net benefit to well-being among populations displaced from "traditional" lifestyles.

\section{THE FUTURE OF HUMAN WELL-BEING AND ECOSYSTEM SERVICES}

The Scenarios Working Group of the Millennium Ecosystem Assessment (MA) comprised about 90 scientists from many countries. This group met repeatedly over several years, working to develop and refine four conceptual models of how the future may unfold. The group used quantitative model results and a qualitative analysis of storylines to seek an understanding of the future status (until 2050) of human well-being and ecosystems services. Two scenarios (TechnoGarden and Adapting Mosaic) assumed "proactive" environmental policies, with a broad recognition of the need to protect, preserve, and restore ecosystems and their services. The other two scenarios (Global Orchestration and Order from Strength) assumed "reactive" environmental policies. The scenarios also differed in their emphasis on the scale and rapidity of economic and technological development.

The group found that well-being and ecosystem services will vary substantially over this range of scenarios, which differ according to their evolution of policies, ecosystem services, and institutions (see Table 1) (Carpenter et al. 2005).

A key finding of the MA is that many ecosystem services are declining. In some cases, these losses of ecosystem services are gradual, whereas in others they are being offset by increases in some other services. In general, regulating and culturally enriching services are being lost at the expense of greater provisioning services. The group found, overall, that well-being is highest in the Global Orchestration scenario, and lowest in the Order from Strength scenario, which focuses primarily on protecting the circumstances of those with existing security.

\section{Human Well-being in Global Orchestration}

The scenario called Global Orchestration focuses on the improvement of material income and education in both industrialized and developing countries. Subsidies and other barriers to free trade are gradually removed, many institutions conducive to well-being improve, and technologies continue to advance. It assumes a reactive, rather than a proactive approach to ecosystem services. There is an assumption, albeit implicit, that the resultant increase in social and human capital will enable 
Table 1. Well-being and ecosystem services vary substantially over these four scenarios, which differ according to their evolution of policies, ecosystem services, and institutions.

Global orchestration. Free trade and a good heart reign in this scenario. There is a determined effort to fight poverty and inequality. As a result, there is a huge boost in food and other provisioning services in developing countries. However, the general approach to ecosystem services is reactive, rather than preventative. The costs are borne by regulating servicessuch as climate change-and a loss in cultural services.

Order from strength. The world fragments into regional markets and alliances. Nations are obsessed with security issues, and the tragedy of the commons deepens. Most categories of ecosystem services decline, especially in developing countries.

TechnoGarden. This is a globally connected world, with abundant green technology, and a focus on preventing ecosystem problems. Food and other provisions increase, although they are not maximized. Climate change, floods, and disease are of less concern. Biodiversity continues to decline.

Adapting mosaic. The emphasis here is on local solutions. Regional politicians and institutions focus on watershed-scale ecosystems to maximize benefits and prevent problems. If it catches on widely, it pays off. Every type of ecosystem service improves in both developing and industrialized nations.

society to cope with any adverse ecological or social surprise that may occur. In this scenario, incomes improve, human capital is enhanced, and material availability increases, because of, among other things, more effective and fairer distributive mechanisms. Increased wealth triggers a greater demand for environmental amenity, and this gradually slows some of the declines in regulating and culturally enriching services.

Global connectedness, cooperation, and emphasis on social as well as economic policies in this scenario improve not only well-being, but also enhance many forms of public good (such as human rights, the rule of law, democracy, political freedom, and peace). The number of underfed children is lowest in this scenario (see Fig. 2). However, the reactive attitude to ecosystem management leaves society vulnerable to adverse surprises, which tend to be belatedly recognized and poorly managed. It is conceivable that some of these adverse ecological surprises (e.g., pollution, erosion, coastal eutrophication, or runaway climate change) could surpass a threshold, overwhelming social capacity and, consequently, damaging human well-being (Walker and Meyers 2004).

The Global Orchestration scenario portrays a significant improvement in provisioning ecosystem services (see Fig. 3) and in human well-being. However, the scenario is vulnerable to adverse ecological surprises, which, if of sufficient scale, may undermine and even reverse the improved human well-being posited in this scenario.

\section{Human Well-being in Order From Strength}

Policy regarding ecosystem services is similarly agnostic in Order from Strength as in Global Orchestration. Wealthy societies assume that technological innovation will overcome any environmental challenges that would otherwise threaten economic growth, and that ecosystem services in industrialized nations will be largely maintained passively, including by static or declining population growth. In developing countries, however, ecosystem services continue to deteriorate because of increasing population (see Fig. 4) and the low rate of technological advance. In contrast to Global Orchestration, there is no organized movement to try to improve social and human capital. In some developing countries, ecosystem scarcity reaches critical thresholds, exacerbating pre-existing tension, and leading to violent conflict. 
Fig. 2. The estimated number of undernourished children in 2050 compared with the present is shown in each scenario. This is lowest in Global Orchestration, but increases in Order from Strength.

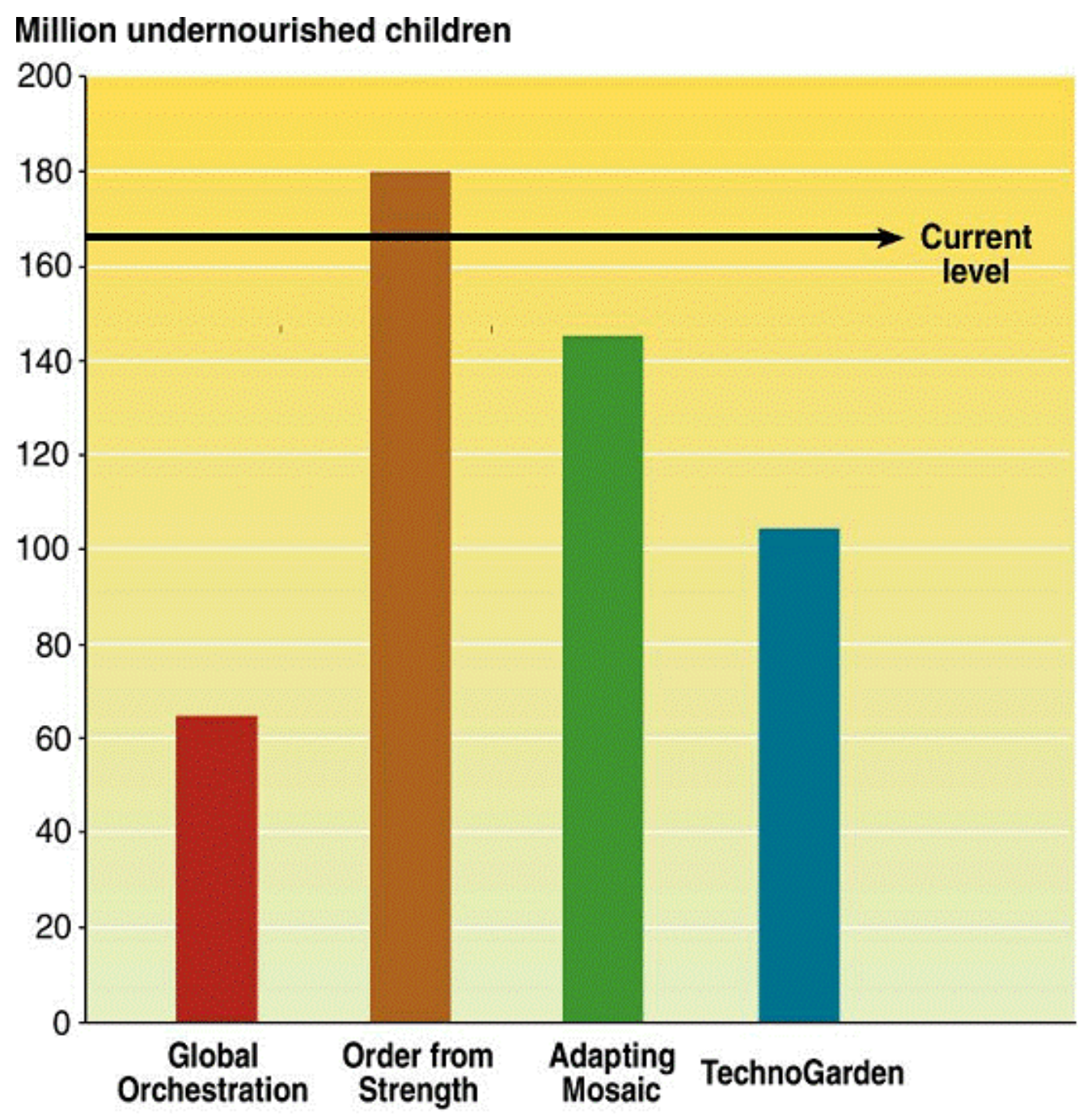

Source: Millennium Ecosystem Assessment

From Millennium Ecosystem Assessment, 2005. Ecosystems and Human Well-being: Synthesis. Island Press, Washington, DC. Copyright (C) 2005 World Resources Institute. Reproduced by permission of World Resources Institute, Washington, D.C. 
Fig. 3. Provisioning, regulating, and culturally enriching services are shown in all four scenarios, compared with the present, for industrial and developing countries.

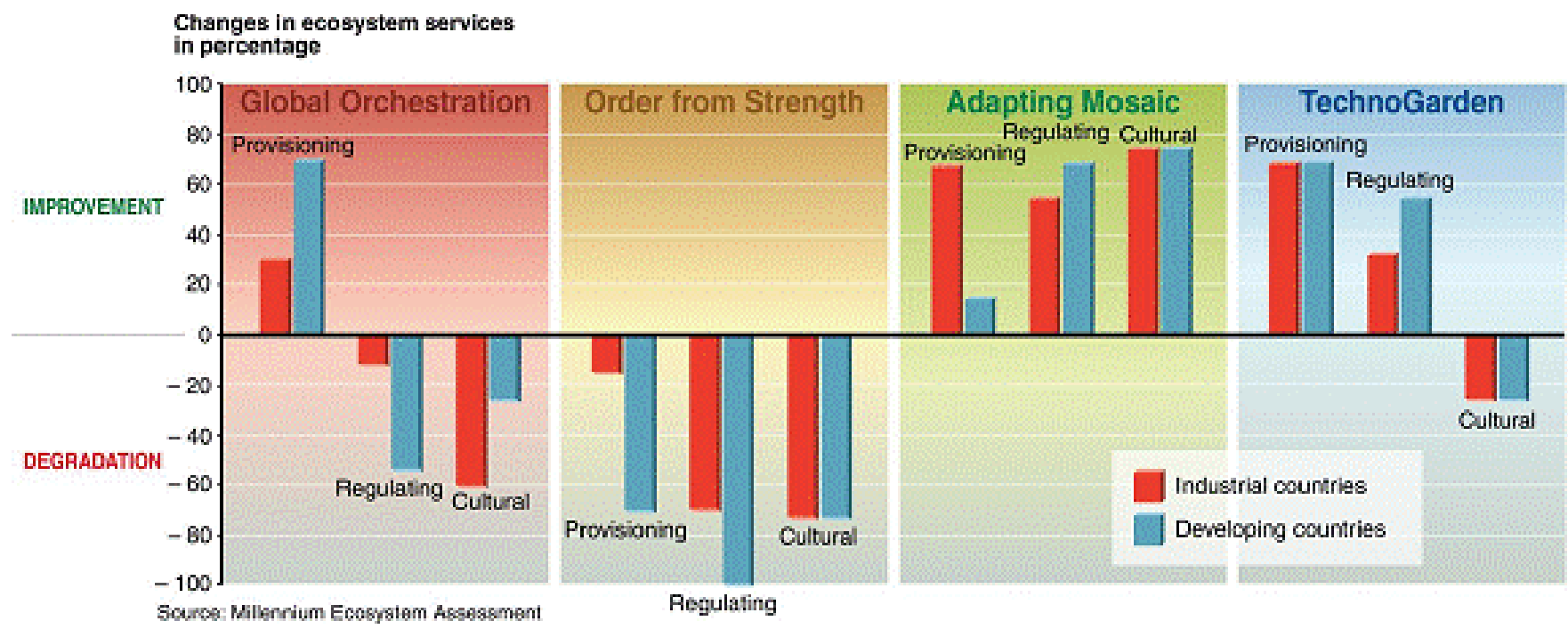

From Millennium Ecosystem Assessment, 2005. Ecosystems and Human Well-being: Synthesis. Island Press, Washington, DC. Copyright (C) 2005 World Resources Institute. Reproduced by permission of World Resources Institute, Washington, D.C.

Policies driven by perceived individual and national self-interest prevail, leaving many barriers to free trade in place. Untrammeled market forces drive global and domestic inequality even higher than at present. Barriers to the movement of trade, people, and information persist, and sophisticated security systems and military forces try to contain and confine the inevitable resentment and backlash that occurs. Economic and environmental policies are geared toward short-term solutions, without concern over either neighbors or successive generations.

In this scenario, a vicious circle is likely to develop, so that deteriorating ecosystem services become both a determinant and a consequence of declining well-being in developing countries. Widespread violent conflict in developing countries is plausible in this scenario, whereas attacks by terrorists emanating from or sympathetic to populations in developing countries may also affect wealthy populations.
Health in developing countries declines as a result of a toxic mixture of poor education, low human capital, high fertility rates, environmental degradation, technological scarcity, and increased inequality. Mortality increases, and both new and old diseases return. Even in industrialized countries, health may decline, as anxiety, stress, obesity, and diabetes increase (Mann 2005, Olshansky et al. 2005). The number of hungry children, most of whom live in developing countries, increases (see Fig. 2).

\section{Human Well-being in Adapting Mosaic and TechnoGarden}

The other two scenarios (Adapting Mosaic and TechnoGarden) share a greater recognition of the importance of ecosystem services for human wellbeing, and gradually develop institutions and mechanisms to ensure a continual supply of ecosystem services. But they differ in the technological ambition and sophistication of the 
Fig. 4. Global population is shown in each scenario from 1900 to 2100. Population increase is lowest in Global Orchestration, peaking at just over eight billion in about 2060. Population growth is highest in Order from Strength, where population plateaus at over ten billion at the end of this century.

\section{Billion persons}

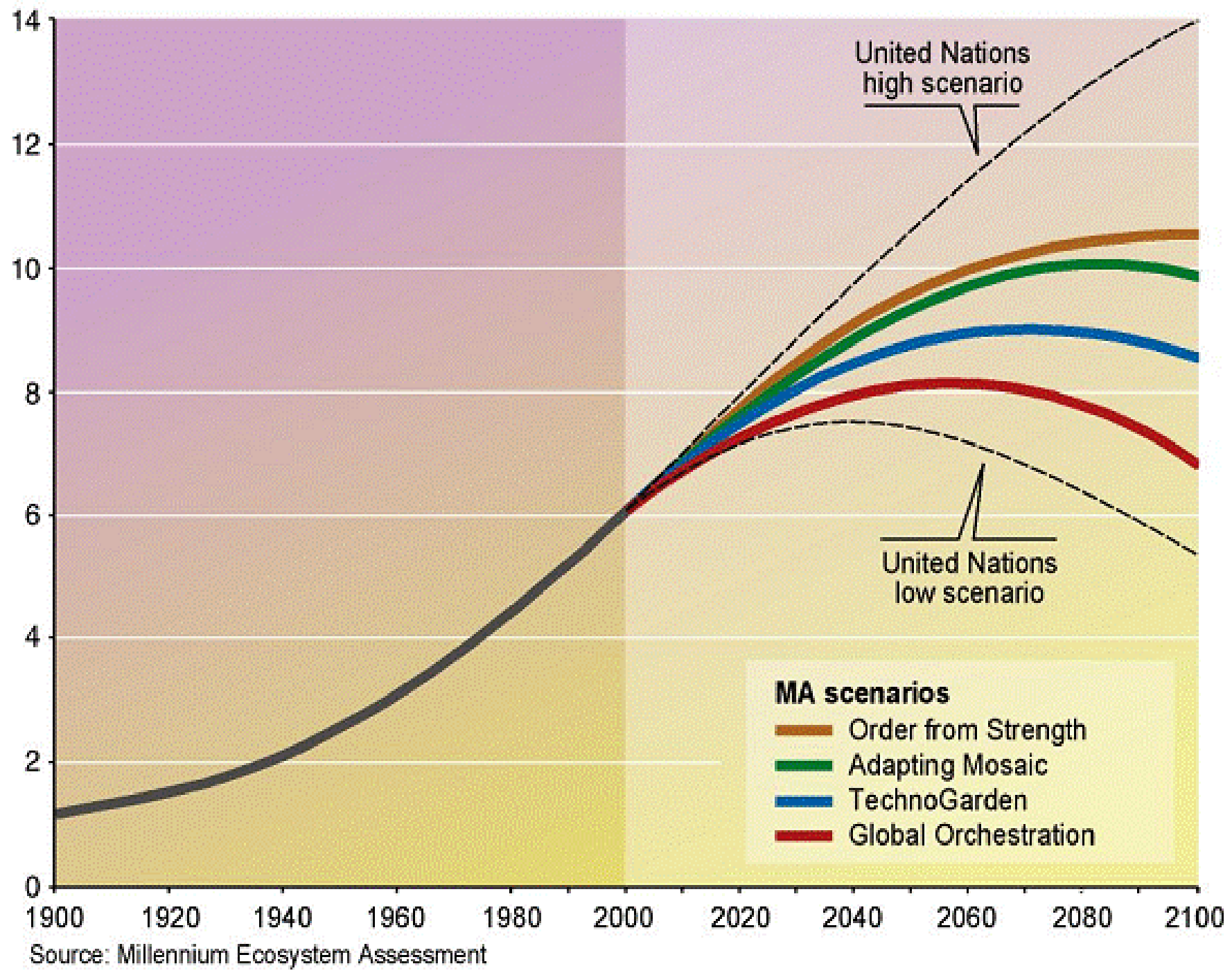

From Millennium Ecosystem Assessment, 2005. Ecosystems and Human Well-being: Synthesis. Island Press, Washington, DC. Copyright (C) 2005 World Resources Institute. Reproduced by permission of World Resources Institute, Washington, D.C. 
means used to achieve this. Adapting Mosaic relies on simpler, community-based means. There is a high degree of local ecological awareness, including both ecological resilience and fragility, and at the same time, sufficient autonomy exists to implement a plethora of local strategies. These qualities facilitate the sustainable use of ecosystems to meet material needs.

In TechnoGarden, more reliance is placed on the development of environmental engineering, on climate and energy-friendly technology, and on new ways of farming that incorporate provisioning with regulating and cultural ecosystem services. This scenario depicts a globally connected society that relies on technological breakthroughs for material provision and ecosystem restoration. This will improve well-being because of improved ecoefficiency in production and optimal control of ecosystems by humans.

The quantitative findings in this scenario show a greatly enhanced agricultural capacity, and an enhancement of provisioning and regulating ecosystem services (see Fig. 3). The number of undernourished children by 2050 falls substantially, though not by as much as in Global Orchestration (see Fig. 2). This is because the social changes posited in TechnoGarden do not assume as great a convergence between industrialized and developing countries as in Global Orchestration.

Market-oriented technology for solutions to environmental problems will ensure sustained provisioning services (food, water, and other material needs) although technology failure and misuse, as well as emphasis on the provisional role of ecosystems could lead to a decline in regulatory, supporting, and culturally enriching ecosystem services.

Health in TechnoGarden improves because of technological breakthroughs, including in preventive medicine, nutrition, pharmaceuticals, vaccines, surgery, and information technology. Environmental conditions improve because of successful environmental engineering. Genetic modification assists the development of "nutraceuticals" that reduce micronutrient deficiency by combining trace elements and high levels of vitamins with staples. Environmental engineering is also used to remediate polluted land, water, and soil, and to reduce the breeding of disease-transmitting vectors, such as mosquitoes.
Technology improves communication, develops substitutes that alleviate resource-based conflicts, and enhances the satisfaction of aesthetic, recreational, and educational needs. This thereby promotes social-cultural relations among societies. Freedom and choice increase, through both additional products and by various production technologies. Similarly, there is increased freedom of communication and movement (Armey 2001).

Overall, however, human well-being does not increase as much in these scenarios as in Global Orchestration. In TechnoGarden, the rate of evolution of institutions is likely to lag behind that of technological development. New technologies may, therefore, be misused in ways that reduce wellbeing. Furthermore, the persistence of trade and other barriers (in both Adapting Mosaic and TechnoGarden) is likely to slow development in poor countries, slowing the rate of poverty alleviation.

\section{ASSESSING THE SCENARIOS}

The real future, however, is unlikely to be as simple as suggested in any individual scenario (Butler 2005, Carpenter et al. 2006). In Adapting Mosaic, the strength of local forces is likely to be balanced by a commensurate weakness of many global institutions. This creates several forms of vulnerability. Local groups, who may themselves be quite harmonious and peaceful, are likely to remain vulnerable to "human predators," including raiders, pirates, and organized criminals. Similarly, good local environmental management may be overwhelmed by large-scale environmental shifts, such as from runaway climate change, fisheries collapses hastened by industrialized fishing trawlers, or widespread coastal eutrophication. Human well-being in this scenario is also placed at risk by a likely failure to effectively respond to any large-scale social crisis, or by the persistence of locally sanctioned customs that harm the well-being of women, minorities, or social reformers and dissidents.

Human well-being in TechnoGarden is sensitive to the rate of evolution of institutions and norms that govern interpersonal relations. If these institutions keep pace with technology, then the outlook for human well-being could be bright. Humanity could use its technologically furnished abundance to improve nutrition, limit disease and exploitation, 
and nurture creativity and freedom. But such a utopia is unlikely-advanced technologies could also be used to foster a dystopia of surveillance, repression, and electronically enforced slavery. Even if institutions are comparatively benign in this scenario, large-scale technological and ecological mistakes and accidents could still occur-and be on a larger scale than in other scenarios, because of the emphasis in this scenario upon novel and powerful technologies. New diseases, new arms races, and new crop vulnerabilities could develop. Although every fire may create its extinguisher, this scenario could unravel if some large-scale responses trigger even larger-scale problems. Social surprises could then develop: an over-reliance on technologies could generate less durable, synthetic relations, harming social cohesion.

There are many difficulties in the Global Orchestration scenario, even if belief is sufficiently suspended to conceive a world without agricultural and other subsidies, and in which powerful populations concede their relative advantage. The 2004 Nobel Prize in Economics was awarded to economists for work that has shown how rarely economic and political actions reach their desired result, even when well intentioned (Seife 2004). Nevertheless, this scenario, even if imperfectly realized, appears to have the greatest chance of stimulating the human capital, the social capital, and the global and local institutions needed to promote large-scale human well-being. Its great risk is that its relative neglect of (especially regulatory and culturally enriching) ecosystem services could precipitate sufficient adverse ecological and social surprises to stress, or even reverse, the improvements in well-being that are forecast.

Order from Strength provides the least desirable future for the global community, although it may be perceived as the most desirable for the small fraction of the global population that is comparatively privileged. However, as with the other scenarios, Order from Strength is unrealistically simplified. Reformers are unlikely to be totally unsuccessful in their attempts to promote global development and to reduce poverty. Powerful populations are also likely, at times, to reduce their relative advantage to both forestall and weaken revolutionary movements.

\section{CONCLUSION}

Ecosystem services are essential, but insufficient for human well-being. Many societies have, in the past, evolved social systems, including customs, acknowledged boundaries, and reciprocities, with which to manage and preserve ecosystem services and human well-being on a local scale. However, the rapid evolution of a globalized society, including its global capacity to harvest and to damage ecosystem services, has overwhelmed the capacity of many of these institutions to cope with contemporary issues. This places the well-being of many - and ultimately perhaps all-populations at risk. None of the four MA scenarios guarantees a perfect future of ample ecosystem services and high human well-being. However, Global Orchestration and Adapting Mosaic, which are both characterized by a more even global distribution of political and economic power promise the greatest gain in human well-being. Improved well-being in TechnoGarden relies critically on the evolution of the institutional frameworks, whereas Order from Strength (which seems to at least offer security and well-being for affluent populations) results in a decline in wellbeing for the poor, and eventually also for the rich.

Levin (2000) concluded "our ability to live sustainably in a global commons is dependent upon adjusting normative behavior, and tightening feedback loops more generally, so that individual actions serve the common good." We concur with this conclusion, but remain sceptical that any of these four scenarios provides a plausible route to enable this, at least over the next 50 years. It seems unwise to base the future of ecosystems and human well-being upon any single strategy, be it economic or technological, of decentralization or of nationalism.

Synergies may exist between the most promising aspect of each scenario in ways that can improve human well-being. For example, the impulse toward mutual development of rich and poor that characterizes Global Orchestration could be harnessed to develop the technologies of TechnoGarden in ways to promote "technological leapfrogging" (Reddy and Goldemberg 1990) in developing countries. Many communities may be attracted to the Adapting Mosaic scenario, provided sufficient global governance to maintain a reasonable level of security is retained. 
The scenarios assume that the future policy direction is determined by either ecological caution or disregard, and that economic policies favor either a global or local focus. Although all scenarios are vulnerable if sufficiently large-scale ecological and social surprises occur, these appear least likely to become catastrophic if the best elements of Global Orchestration, Adapting Mosaic, and TechnoGarden can be simultaneously developed. Finally, even though Order from Strength provides the least favorable future, its central insight - the recognition that well-being requires security-must be integrated into any sustainable future.

Responses to this article can be read online at:

http://www.ecologyandsociety.org/voll1/iss1/art30/responses/

\section{Acknowledgments:}

We thank the funders, organizers and participants of Millennium Ecosystem Assessment, particularly our colleagues in the Scenarios Working Group.

\section{LITERATURE CITED}

Adams, W. M., D. Brockington, J. Dyson, and B. Vira. 2003. Managing tragedies: understanding conflict over common pool resources. Science 302:1915-1916.

André, C., and J.-P. Platteau. 1998. Land relations under unbearable stress: Rwanda caught in the Malthusian trap. Journal of Economic Behavior and Organization 34:1-47.

Armey, D. 2001. How technology increases freedom. Freedomworks, Washington, D.C, USA.

Atran, S., D. Medin, N. Ross, E. Lynch, J. Coley, E. U. Ek, and V. Vapnarsky. 1999. Folkecology and commons management in the Maya Lowlands. Proceedings of the National Academy of Sciences 96:7598-7603.

Balmford, A., L. Bennun, B. Brink, D. Cooper, I. M. Côté, P. Crane, A. Dobson, N. Dudley, I. Dutton, R. E. Green, R. D. Gregory, J. Harrison, E. T. Kennedy, C. Kremen, N. Leader-Williams, T. E. Lovejoy, G. Mace, R. May, P. Mayaux, P.
Morling, J. Phillips, K. Redford, H. Taylor, T. H. Ricketts, J. P. Rodríguez, M. Sanjayan, P. J. Schei, A. S. van Jaarsveld, and B. A. Walther. 2005. The Convention on Biological Diversity's 2010 target. Science 307:212-213.

Berkes, F. 2003. Sacred ecology. Traditional ecological knowledge and resource management. Taylor and Francis, Philadelphia, Pennsylvania, USA.

Berkes, F., M. Kislalioglu, C. Folke, and M. Gadgil. 1998. Exploring the basic ecological unit: ecosystem-like concepts in traditional societies. Ecosystems 1:409-415.

Blais, J. M., D. W. Schindler, D. C. G. Muir, L. E. Kimpe, D. B. Donald, and B. Rosenberg. 1998. Accumulation of persistent organochlorine compounds in mountains of western Canada. Nature 395:585588.

Bryce, J., C. Boschi-Pinto, K. Shibuya, R. E. Black, and WHO Child Health Epidemiology Reference Group. 2005. WHO estimates of the causes of death in children. The Lancet 365:11471152.

Butler, C. D. 2005. Peering into the fog: ecologic change, human affairs and the future. EcoHealth 2:17-21.

Butler, C. D., R. Chambers, K.Chopra, P. Dasgupta, A. Duraiappah, P. Kumar, A. J. McMichael, and N. Wen-Yuan (authors alphabetical). 2003. Ecosystems and human wellbeing, Pages 71-84 in Millennium Ecosystem Assessment, editor. Ecosystems and human wellbeing. A framework for assessment. Island Press, Washington, D.C., USA.

Butler C. D., and A. J. McMichael. 2006. Environmental health. Pages 318-336 in V. Sidel and B. Levy, editors. Social injustice and public health. Oxford University Press, Oxford, UK.

Carpenter, S., E. Bennett, and G. Peterson. 2006. Editorial: Special feature on scenarios for ecosystem services. Ecology and Society, in press.

Carpenter, S. R., P. L. Pingali, E. M. Bennett, and M.B.Zurek, editors. 2005. Ecosystems and human well-being. Volume 2. Scenarios. Island Press, Washington, D.C., USA. 
Danielsen, F., M. K. Sørensen, M. F. Olwig, V. Selvam, F. Parish, N. D. Burgess, T. Hiraishi, V. N. Karunagaran, M. S. Rasmussen, L. B. Hansen, A. Quarto, and N. Suryadiputra. 2005. The Asian tsunami: a protective role for coastal vegetation. Science 310:643.

de Onis, M., M. Blossner, E. Borghi, R. Morris, and E. A. Frongillo. 2004. Methodology for estimating regional and global trends of child malnutrition. International Journal of Epidemiology 33:1260-1270.

de Waal, A., and A. Whiteside. 2003. New variant famine: AIDS and food crisis in southern Africa. The Lancet 362:1234-1237.

Dillingham, R., and R. L. Guerrant. 2004. Childhood stunting: measuring and stemming the staggering costs of inadequate water and sanitation. The Lancet 363:94-95.

Elvin, M. 2004. The retreat of the elephants. An environmental history of China. Yale University Press, New Haven, Connecticut, USA.

Falkowski, P., R. J.Scholes, E. Boyle, J. Canadell, D. Canfield, J. Elser, N. Gruber, K. Hibbard, P. Hogberg, S. Linder, F. T. Mackenzie, B. Moore, T. Pedersen, Y. Rosenthal, S. Seitzinger, V. Smetacek, and W.Steffen. 2000. The global carbon cycle: a test of our knowledge of Earth as a system. Science 290:291-296.

FAO and CIFOR. 2005. Forests and floods. Drowning in fiction or thriving on facts? RAP Publication 2005/03, Forest Perspectives 2.

Foley, J. A., M. T. Coe, M. Scheffer, and G. Wang. 2003. Regime shifts in the Sahara and Sahel: interactions between ecological and climatic systems in Northern Africa. Ecosystems 6:524-539.

Folke, C. 2004. Traditional knowledge in socialecological systems [editorial]. Ecology and Society 9(3):7. [online] URL: http://www.ecologyandsociety. org/vol9/iss3/art7/.

Friedmann, E., and S. Thomas. 1995. Pet ownership, social support, and one-year survival after acute myocardial infarction in the cardiac arrhythmia suppression trial (CAST). American Journal of Cardiology 76:1213-1217.
Frumkin, H. 2002. Beyond toxicity: human health and the natural environment. American Journal of Preventive Medicine 20:234-240.

Grantham-McGregor, S. 2002. Linear growth retardation and cognition [commentary]. The Lancet 359:111-114.

Hellin, J., M. Haigh, and F. Marks. 1999. Rainfall characteristics of Hurricane Mitch. Nature 359:316.

Jepson, P., J. K. Jarvie, K. MacKinnon, and K. A. Monk. 2001. The end for Indonesia's lowland forests? Science 292:859-861.

Kirch, P. V. 1997. Microcosmic histories: island perspectives on "global" change. American Anthropologist 99:30-42.

Lelieveld, J., H. Berresheim, S. Borrmann, P. J. Crutzen, F. J. Dentener, H. Fischer, J. Feichter, P. J. Flatau, J. Heland, R. Holzinger, R. Korrmann, M. Lawrence, Z. Levin, K. M. Markowicz, N. Mihalopoulos, A. Minikin, V. Ramanathan, M. de Reus, G. J. Roelofs, H. A. Scheeren, J. Sciare, H. Schlager, M. Schultz, P. Siegmund, B. Steil, E. G. Stephanou, P. Stier, M. Traub, C. Warneke, J. Williams, and H. Ziereis. 2002. Global air pollution crossroads over the Mediterranean. Science 298:789-791.

Levin, S. A. 2000. Multiple scales and the maintenance of biodiversity. Ecosystems 3:498506.

Macintyre, M., and S. Foale. 1997. Politicised ecology: local responses to mining in Papua New Guinea. Resource Management in Asia-Pacific Working Paper No. 33. National Centre for Development Studies and Resource Management in Asia-Pacific Project, Australian National University, Canberra, Australia. [online] URL: http://rspas.anu. edu.au/rmap/workingpapers.php.

Mann, C. C. 2005. Provocative study says obesity may reduce U.S. life expectancy. Science 307:1716-1717.

Mukta, P., and D. Hardiman. 2000. The political economy of nostalgia. Capitalism Nature Socialism 11(1):113-133.

Olshansky, S. J., D. J. Passaro, R. C. Hershow, J. Layden, B. A. Carnes, J. Brody, L. Hayflick, R. 
N. Butler, D. B. Allison, and D. S. Ludwig. 2005. A potential decline in life expectancy in the United States in the 21st century. New England Journal of Medicine 352:1138-1145.

Page, S. E., F. Siegert, J. O. Rieley, H.-D. V. Boehm, A. Jaya, and S. Limin. 2002. The amount of carbon released from peat and forest fires in Indonesia during 1997. Nature 420:61-65.

Patz, J. A., P. Daszak, G. M. Tabor, A.A. Aguirre, M. Pearl, J. Epstein, N. D. Wolfe, A. M. Kilpatrick, J. Foufopoulos, D. Molyneux, D. J. Bradley, and members of the Working Group on Land Use Change and Disease Emergence. 2004. Unhealthy landscapes: policy recommendations on land use change and infectious disease emergence. Environmental Health Perspectives 112:10921098.

Pogge, T. 2004. The first United Nations Millennium Development Goal: a cause for celebration? Journal of Human Development 5 (3):377-397.

Price, T. D., and G. M. Feinman, editors. 1995. Foundations of social inequality. Plenum Publishing Corporation, New York, New York, USA.

Primavera, J. H. 2005. Mangroves, fishponds, and the quest for sustainability. Science 310:57-59.

Ramakrishnan, P., K. Saxena, and U. Chandrashekara. 1998. Conserving the sacred: for biodiversity management. UNESCO, Oxford, UK; New Delhi, India.

Reddy A. K. N., and J. Goldemberg. 1990. Energy for the developing world. Scientific American $\mathbf{2 6 3}$ (3):63-72.

Sanchez, P. A., and M. S. Swaminathan. 2005. Hunger in Africa: the link between unhealthy people and unhealthy soils. The Lancet 365:442-444.

Seife, C. 2004. Macroeconomists showed why good intentions go wrong. Science 306:401.

Sen, A. K. 1981. Poverty and famines: an essay on entitlement and deprivation. Clarendon Press, Oxford, UK; New Delhi, India.

Serpell, J. 1991. Beneficial effects of pet ownership on some aspects of human health and behaviour. Journal of the Royal Society of Medicine 84:717-20.

Siegert, F., G. Ruecker, A. Hinrichs, and A. A. Hoffmann. 2001. Increased damage from fires in logged forests during droughts caused by El Niño. Nature 414:437-440.

Tickell, C. 2004. The decline of China's environment. Nature 430:505.

Tong, S., Y. E. von Schirnding, and T. Prapamontol. 2000. Environmental lead exposure: a public health problem of global dimensions. Bulletin of the World Health Organization 78:10681077.

Trenberth, K. E., and T. J. Hoar. 1996. The 1995 El Niño-Southern Oscillation event: longest on record. Geophysical Research Letters 23:57-60.

Ulrich, R. S. 1984. View through a window may influence recovery from surgery. Science 224:420 421.

Verhye, W. H. 2000. Local farmers would be able to feed Africa if they were given the chance. Nature 404:431.

Walker, B., and J. A. Meyers. 2004. Thresholds in ecological and social-ecological systems: a developing database. Ecology and Society 9(2):3. [online] URL: http://www.ecologyandsociety.org/vol9/ iss $2 / \operatorname{art} 3 /$.

Webster, P. 2004. Study finds heavy contamination across vast Russian Arctic. Science 306:1875.

Webster, P. 2005. Health in the Arctic Circle. The Lancet 365:741-742.

Wilson, E. O. 1984. Biophilia. Harvard University Press, Cambridge, Massachussetts, USA.

Woodham-Smith, C. 1962. The great hunger. Ireland 1845-1849 Hamish Hamilton, London, UK.

Zinsstag, J., and M. G. Weiss. 2001. Livestock diseases and human health [editorial]. Science 294:477. 